\title{
Changes in Trauma Service Professional Fee Coding Following Electronic Health Record Implementation
}

\author{
Edgardo S Salcedo*, Brent C Pottenger, Joseph M Galante and David H Wisner
}

Department of Surgery, UC Davis School of Medicine, USA

\begin{abstract}
Background: Implementing an electronic health record (EHR) system is an expensive and large-scale project. Few studies have examined the impact of inpatient EHRs on documentation, coding levels, and professional fee reimbursement. Trauma and Emergency Surgery services are ideal for studying this question given their high percentage of inpatient evaluation and management ( $E$ \& $M)$ work. This study elucidates effects of an EHR on coding practices for the inpatient Trauma and Emergency Surgery Service at an academic level I Trauma Center. We hypothesize that EHR implementation leads to higher coding levels and increased professional fee revenue.
\end{abstract}

Methods: De-identified data was extracted from the University Health System Consortium and Association of American Medical Colleges Faculty Practice Solution Center database. Our medical center transitioned from written physician notes to the EHR in May 2009. The database was queried for notes written by the Trauma and Emergency Surgery service in calendar years 2008 and 2011 to compare years before and after EHR implementation. The CPT codes of interest were for E \& M Initial Hospital Care (99221, -2, and -3) and Subsequent Hospital Care (99231, -2 , and -3 ). Coding levels were linked to standard Medicare Relative Value Units. Professional coders were used throughout and coding guidelines were unchanged over the study period.

Results: Coding levels for Initial Hospital Care notes increased immediately and markedly. Revenue from these codes increased by $28.1 \%$ while Subsequent Hospital Care codes increased less dramatically by $1.7 \%$.

Conclusions: The increase in higher E \& M coding levels due to HER implementation was financially significant, immediate, and durable. The increase in total Initial Hospital Care notes resulted from improved coder note recognition and higher note quality. Revenue increased measurably.

Keywords: Electronic health record; Coding; Billing; Trauma

\section{Introduction}

Implementing an Electronic Health Record (EHR) system is an expensive, large-scale, multi-level organizational project. Hospitals, health systems, and clinics have adopted EHRs for reasons ranging from financial to legal to operational. EHRs have perceived benefits in clinical efficiency, communication, and continuity of care [1]. The effects of EHR have been studied in the outpatient setting. Some studies have reported positive returns on investment and improved productivity and quality [2-7], but others have not [8]. Fewer studies have examined the impact of inpatient EHRs, and some healthcare systems have been hesitant to adopt them because they are expensive and potentially cumbersome $[9,10]$. Examination of the effect of inpatient EHRs on documentation coding levels and professional fee reimbursement are sparse $[11,12]$ We investigated the impact of an inpatient EHR on coding levels and reimbursement for a busy trauma and emergency surgery service at a large teaching hospital. Trauma and emergency surgery is the ideal type of surgical service to study because of the high percentage of inpatient cognitive evaluation and management work done by the average trauma and emergency surgeon relative to other surgical specialties [13].

This retrospective study's purpose was to elucidate the effect of switching to an EHR on coding practices for the inpatient trauma and emergency surgery service at the University of California, Davis, Medical Center (UCDMC), an academic level I Trauma Center. Our hypothesis was that the implementation of an EHR would result in more complete notes and higher levels of coding, which in turn would increase professional fee revenue.

\section{Materials and Methods}

This study was approved by the Institutional Review Board of The
University of California, Davis. De-identified data was extracted from the University Health System Consortium and Association of American Medical Colleges Faculty Practice Solution Center Database (FPSC). The FPSC is an analysis and benchmarking tool created from the direct download of coding data from over 80 participating academic medical centers. Both evaluation and management (E \& M) and procedural coding are collected. Data can be sorted to focus on specific surgeons and services. Our analysis concentrated on surgeon members of the trauma and emergency surgery service who care for all trauma patients and $75 \%$ of the emergency surgery patients at the institution. The service manages its own critical care patients.

UCDMC transitioned from hand-written notes to the EHR in May 2009. The transition was done all at once in a "big bang" approach wherein all of the note creation was switched from paper to electronic in a single day. The FPSC database was queried for notes written in calendar years 2008 and 2011 for a comparison of the year before and the year after implementation of the EHR. Calendar years 2009 and 2010 were not used for before and after comparisons to minimize any

*Corresponding author: Edgardo S Salcedo, Department of Surgery, UC Davis School of Medicine, 2315 Stockton Blvd, Room 4206, Sacramento, CA 95817, USA Tel: 916-734-3980; Fax: 916-734-7755; E-mail: edgardo.salcedo@ucdmc.ucdavis.edu

Received September 21, 2014; Accepted October 26, 2014; Published October 28, 2014

Citation: Salcedo ES, Pottenger BC, Galante JM, Wisner DH (2014) Changes in Trauma Service Professional Fee Coding Following Electronic Health Record Implementation. J Trauma Treat 3: 215. doi:10.4172/2167-1222.1000215

Copyright: (c) 2014 Salcedo ES, et al. This is an open-access article distributed under the terms of the Creative Commons Attribution License, which permits unrestricted use, distribution, and reproduction in any medium, provided the original author and source are credited. 
potential transitional effects as the faculty group, coders, and health system converted to the EHR. However, data was analyzed for the entire period between January 1, 2008 and December 31, 2011 to track trends over time.

The CPT codes of interest were for Initial Hospital Care (99221, 99222, and 99223) and for Subsequent Hospital Care (99231, 99232, and 99233), representing initial history and physical notes and subsequent progress notes, respectively. Coding levels were linked to standard Medicare relative value units (RVUs), with higher levels of coding generating higher levels of RVUs. Paid medical abstractor coders performed all coding following both institutional and Medicare guidelines that were unchanged throughout the study time period.

To quantify the effect of coding changes on revenue, servicespecific data from an institutional database (Decision Line) was used to generate CPT-code-specific data for revenue per RVU. For example, the average dollars of revenue generated per RVU when a note was coded out as a mid-level Initial Hospital Care note (99222) or as a low level Subsequent Hospital Care note (99231) were calculated. CPT-code-specific RVU and service-specific revenue per RVU data for 2011 was used for all analyses to determine the effects of coding level changes on revenue as an isolated variable. Using data from a specific year avoided any influence of payer mix or reimbursement rate changes over time. Using the above approach, the revenue per RVU that the service generated in 2008 and 2011 for each of the CPT codes of interest was calculated.

The total and the proportion of trauma service notes coded at each of the three coding levels for Initial Hospital Care and Subsequent Hospital Care were determined for each year. These proportions were used to calculate the revenue generated by each CPT code in a given calendar year. To focus solely on the effect of coding level changes and to eliminate any effects of changes in patient volume, the revenue generated by an average 100 patients in 2008 and 2011 was calculated and compared.

The Decision Line hospital database was used to quantify admission volume over time with data that was independent of CPT and coding level data.

\section{Results}

After switching to an EHR, a dramatic and sustained increase in Initial Hospital Care coding levels was observed. This trend is depicted in Figure 1 and in Table 1. The percentage of notes coded at the highest level for Initial Hospital Care was $12.7 \%$ in 2008 and 55.4\% in 2011. A less dramatic increase in the percentage of notes coded at the highest level for Subsequent Hospital Care was also seen, increasing from $29.3 \%$ in 2008 to $37.1 \%$ in 2011 (Figure 2 and Table 1 ).

For Initial Hospital Care, revenue per 100 notes was $28.1 \%$ higher in 2011 after EHR implementation as compared to 2008 before EHR implementation. The increase for Subsequent Hospital Care was a more modest $1.7 \%$ (Table 2).

\section{Discussion}

The landscape of health care delivery is changing dramatically and quickly with rapid technological advances. Electronic Health Records, especially full EHR, remain relatively uncommon, but the number of hospitals adopting elements of an EHR is increasing rapidly, with substantial expansions in EHR capability seen over the matter of just a few years [14]. Academic medical centers and hospitals in urban settings have been more likely to implement an HER [14], but physician practices and smaller institutions are also adopting EHR more and more each year [15]. The US government is aggressively encouraging the transition from paper to digital records with a variety of incentives for EHR adoption and even penalties for failing to make the change [16]. It is clear that the EHR will be the main documentation and ordering system in our hospitals within the next generation.

The advantages and disadvantages of EHRs have been studied and discussed. Clinically, EHRs improve adherence to evidence-based guidelines for best-practice care measures [17]. In both inpatient and outpatient settings, EHRs increase rates of administering recommended vaccinations [18], increase use of appropriate chemical

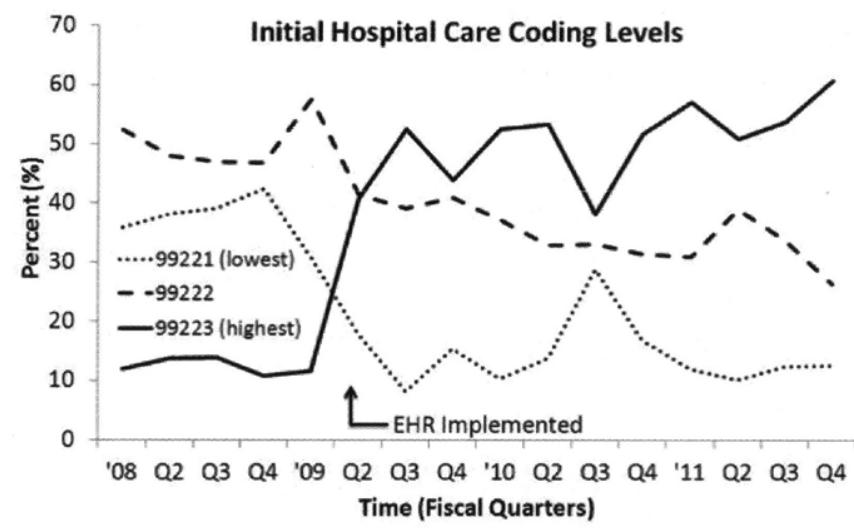

Figure 1: Distribution of coding levels over time. EHR instituted in Q2 of 2009.

\begin{tabular}{|c|c|c|c|c|}
\hline $\begin{array}{c}\text { CPT Code } \\
\text { Initial Hospital Care }\end{array}$ & Total 2008 & 2008 Percent & Total 2011 & 2011 Percent \\
\hline 99221 & 618 & 38.9 & 319 & 11.8 \\
\hline 99222 & 769 & 48.4 & 889 & 32.8 \\
\hline 99223 & 201 & 12.7 & 1,503 & 55.4 \\
\hline Total & 1,588 & 100 & 2,711 & 100 \\
\hline $\begin{array}{c}\text { Subsequent } \\
\text { Hospital Care }\end{array}$ & & & & \\
\hline 99231 & 250 & 2.1 & 1,335 & 9.7 \\
\hline 99232 & 8,082 & 68.6 & 7,284 & 53.2 \\
\hline 99233 & 3,445 & 29.3 & 5,083 & 37.1 \\
\hline Total & 11,777 & 100 & 13,702 & 100 \\
\hline
\end{tabular}

Table 1: Total notes and distribution by coding level for 2008 and 2011.

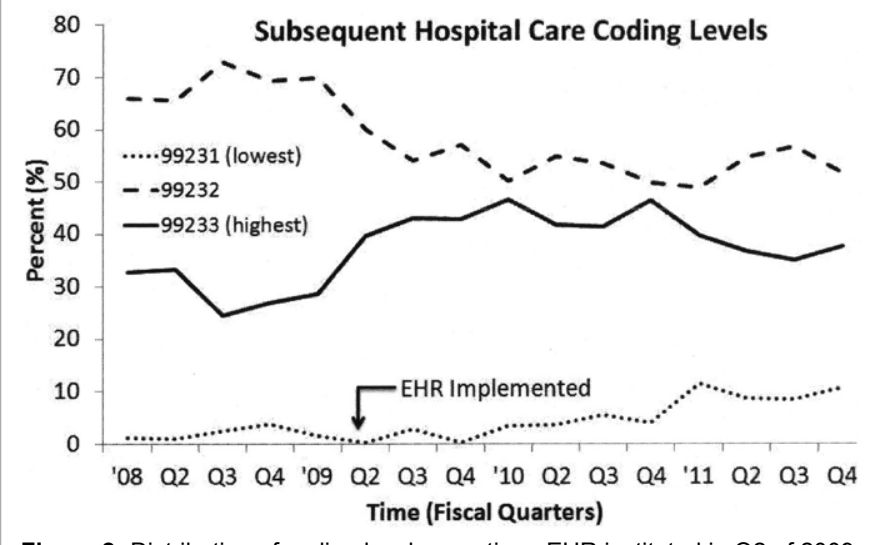

Figure 2: Distribution of coding levels over time. EHR instituted in Q2 of 2009. 


\begin{tabular}{|c|c|c|c|}
\hline CPT Code & $\begin{array}{c}\mathbf{\$} / \mathbf{1 0 0} \text { Notes } \\
\mathbf{2 0 0 8}\end{array}$ & $\mathbf{\$} / \mathbf{1 0 0}$ Notes 2011 & $\begin{array}{c}\text { Revenue } \\
\text { Change \% }\end{array}$ \\
\hline Initial Hospital Care, Total & $11,129.67$ & $14,252.41$ & $+28.06 \%$ \\
\hline Subsequent Hospital Care & $6,460.03$ & $6,568.01$ & $+1.67 \%$ \\
\hline
\end{tabular}

Table 2: Realized revenue and revenue change per 100 notes by coding level and overall.

thromboembolic prophylaxis [19] and decrease the incidence of pressure ulcers [20]. Other studies show reductions in the ordering of laboratory tests [21] and imaging studies [22] using targeted criteria embedded within the EHR, while others observe association with decreases in length of stay, infection rates, and mortality rates [23] Many of these studies highlight the advantages of the clinical decision support (CDS) and computerized physician order entry (CPOE) aspects of an EHR. EHRs also improve the ability to conduct research by storing large volumes of data that are easily accessible for detailed analyses.

There are also potential disadvantages associated with the use of EHR systems. They have yet to achieve some of their purported benefits in some settings [24] these barriers to optimal, meaningful EHR use are financial, operational, and functional. They are expensive to install and implement [25] though their increasing prevalence may drive down startup costs to some degree. Maintenance costs are also significant. Providers require training and support in the use of EHR systems in addition to periodic software and hardware upgrades and replacements [26] Implementing an EHR system also results in a temporary loss of productivity from providers struggling to learn the new system [27], while others have either experienced decreased efficiency during early stages of implementation [28] or have seen implementation proceed much more slowly than expected [29]. There is also the potential for practices to become over dependent on EHR technology, making it difficult for them to continue providing efficient patient care if the systems are unavailable for maintenance or if they malfunction or lose power. Overall, costs can be very high and even prohibitive for instituting an EHR for some practices [1], highlighting the need to clearly define all mechanisms by which an EHR can increase physician or institutional revenue [30].

The effects of EHR adoption on inpatient coding practices has not been extensively studied and has not been evaluated at all for trauma and emergency surgery services. Trauma and emergency surgical services coding is in some respects ideal for studying the effects on a surgical practice of EHR adoption. Much of the coding generated by a trauma and emergency surgeon comes from evaluation and management codes, and inpatient evaluation and management coding is a much higher percentage of overall coding for a trauma and emergency surgery service than it is for other surgical practices [13].

Our adoption of an EHR for inpatient physician documentation was done all at once, institution-wide, allowing for a comparison of coding before versus after the conversion. We identified a rapid, significant, and sustained increase in coding levels for Initial Hospital Care notes after EHR adoption. There was also an increase, albeit much less dramatic, in coding levels for Subsequent Hospital Care notes.

The reasons for our findings are likely multifactorial. Implementing an EHR facilitated the use of templates by resident and attending surgery staff, to assure the essential elements of higher-level notes were not overlooked. Templates conducive to high quality note creation are easy to develop and are universally utilized in an EHR environment. The transition from handwritten notes also improved the legibility and uniformity of notes, making it easier for coders to identify and process them more effectively. Auto population of demographic, laboratory, and other data also increased the quality of the notes from a coding perspective. Ease of access to the EHR for our coding and billing staff and the use of electronic signatures made note capture much easier and more complete and minimized the chances of missing billable notes.

Our health system uses professional coders for inpatient coding, a potential limitation for generalizing these results to other institutions where physicians do their own coding. We believe that note quality actually does improve with the implementation of an EHR, however, and feel that similar results would be seen on trauma and emergency services where physicians do their own coding, provided that the physicians are familiar with the requirements for the different coding levels.

Another potential limitation is that we did not include critical care codes in our analysis. Critical care codes are an extremely important contributor to revenue for most trauma and emergency surgery practices [13]. We chose not to include critical care codes because they are time-based and rely much less heavily on note quality. Consequently, critical care codes are much less likely to be affected by the implementation of an EHR.

Electronic health records are here to stay and will increasingly dominate medical record keeping and professional fee coding. Electronic health records clearly have both advantages and disadvantages, but the hope is that the advantages will ultimately outweigh the disadvantages, including when it comes to quantifiable costs and benefits as measured in dollars. A fairly convincing case has been made that EHRs are, in the long run, a good investment for institutions, [2-7,17,26,31-34] but there is much less information about the effects of an EHR on physician coding and professional fee revenue. Elucidating these effects is becoming increasingly important as payors are starting to audit how EHR charting behaviors influence billing patterns [35]. Our study demonstrates a positive effect on professional coding and revenue with the implementation of an EHR for inpatient evaluation and management services provided by a busy trauma and emergency surgery service.

\section{References}

1. Menachemi N, Collum TH (2011) Benefits and drawbacks of electronic health record systems. Risk Manag Healthc Policy 4: 47-55.

2. Barlow S, Johnson J, Steck J (2004) The economic effect of implementing an EMR in an outpatient clinical setting. J Healthc Inf Manag 18: 46-51.

3. Cheriff AD, Kapur AG, Qu M, Cole CL (2010) Physician productivity and the ambulatory EHR in a large academic multi-specialty physician group. Int J Med Inform 79: 492-500.

4. Grieger DL, Cohen SH, Krusch DA (2007) A pilot study to document the return on investment for implementing an ambulatory electronic health record at an academic medical center. J Am Coll Surg 205: 89-96.

5. Kern LM, Barrón Y, Dhopeshwarkar RV, Edwards A, Kaushal R; HITEC Investigators (2013) Electronic health records and ambulatory quality of care. J Gen Intern Med 28: 496-503.

6. Lau F, Price M, Boyd J, Partridge C, Bell H, et al. (2012) Impact of electronic medical record on physician practice in office settings: a systematic review. BMC Med Inform Decis Mak 12: 10

7. Samaan ZM, Klein MD, Mansour ME, DeWitt TG (2009) The impact of the electronic health record on an academic pediatric primary care center. J Ambul Care Manage 32: 180-187.

8. Bloom MV, Huntington MK (2010) Faculty, resident, and clinic staff's evaluation of the effects of EHR implementation. Fam Med 42: 562-566.

9. Boonstra A, Broekhuis M (2010) Barriers to the acceptance of electronic medica records by physicians from systematic review to taxonomy and interventions. BMC Health Serv Res 10: 231. 
Citation: Salcedo ES, Pottenger BC, Galante JM, Wisner DH (2014) Changes in Trauma Service Professional Fee Coding Following Electronic Health Record Implementation. J Trauma Treat 3: 215. doi:10.4172/2167-1222.1000215

10. Yan H, Gardner R, Baier R (2012) Beyond the focus group: understanding physicians' barriers to electronic medical records. Jt Comm J Qual Patient Saf 38: 184-191.

11. Pitts SR (2012) Higher-complexity ED billing codes--sicker patients, more intensive practice, or improper payments? N Engl J Med 367: 2465-2467.

12. Dezfuli B, Smith JL (2012) Level of billing as a function of resident documentation and orthopedic subspecialty at an academic multispecialty orthopedic surgery practice. Orthopedics. 11: e1655-1658.

13. Galante JM, Phan HH, Wisner DH (2010) Trauma surgery to acute care surgery: defining the paradigm shift. J Trauma 68: 1024-1031.

14. Jha AK, DesRoches CM, Campbell EG, Donelan K, Rao SR, et al. (2009) Use of electronic health records in U.S. hospitals. N Engl J Med 360: 1628-1638.

15. Jamoom E, Beatty P, Bercovitz A, Woodwell D, Palso K, et al. (2012) Physician adoption of electronic health record systems: United States, 2011. NCHS Data Brief : 1-8.

16. Patel V, Jamoom E, Hsiao CJ, Furukawa MF, Buntin M (2013) Variation in electronic health record adoption and readiness for meaningful use: 20082011. J Gen Intern Med 28: 957-964.

17. Silow-Carroll S, Edwards JN, Rodin D (2012) Using electronic health records to improve quality and efficiency: the experiences of leading hospitals. Issue Brief (Commonw Fund) 17: 1-40.

18. Ledwich LJ, Harrington TM, Ayoub WT, Sartorius JA, Newman ED (2009) Improved influenza and pneumococcal vaccination in rheumatology patients taking immunosuppressants using an electronic health record best practice alert. Arthritis Rheum. 61:1505-1510.

19. Kucher N, Koo S, Quiroz R, Cooper JM, Paterno MD, et al. (2005) Electronic alerts to prevent venous thromboembolism among hospitalized patients. N Engl J Med 352: 969-977.

20. Anderson JA, Willson P, Peterson NJ, Murphy C, Kent TA (2010) Prototype to practice: Developing and testing a clinical decision support system for secondary stroke prevention in a veterans healthcare facility. Comput Inform Nurs.6: 353-363.

21. Palen TE, Price DW, Snyder AJ, Shetterly SM (2010) Computerized aler reduced D-dimer testing in the elderly. Am J Manag Care 16: e267-275.

22. Solberg LI, Wei F, Butler JC, Palattao KJ, Vinz CA, et al. (2010) Effects of electronic decision support on high-tech diagnostic imaging orders and patients. Am J Manag Care 16: 102-106.
23. Xue $\mathrm{Y}$, Liang $\mathrm{H}$, Wu X, Gong $\mathrm{H}$, Li B, et al. (2012) Effects of electronic medical record in a Chinese hospital: a time series study. Int J Med Inform 81: 683-689.

24. Black AD, Car J, Pagliari C, Anandan C, Cresswell K, et al. (2011) The impact of eHealth on the quality and safety of health care: a systematic overview. PLoS Med 8: e1000387.

25. Yoon D, Chang BC, Kang SW, Bae H, Park RW (2012) Adoption of electronic health records in Korean tertiary teaching and general hospitals. Int $\mathrm{J} \mathrm{Med}$ Inform 81: 196-203.

26. Takian A, Sheikh A, Barber N (2012) We are bitter, but we are better off: case study of the implementation of an electronic health record system into a mental health hospital in England. BMC Health Serv Res 12: 484

27. Wang T, Biedermann S (2010) Running the numbers on an EHR. Applying cost-benefit analysis in EHR adoption. J AHIMA 81: 32-36.

28. Furukawa MF, Raghu TS, Shao BB (2010) Electronic medical records and cost efficiency in hospital medical-surgical units. Inquiry 47: 110-123.

29. Sheikh A, Cornford T, Barber N, Avery A, Takian A, et al. (2011) Implementation and adoption of nationwide electronic health records in secondary care in England: final qualitative results from prospective national evaluation in "early adopter" hospitals. 17: 343:d6054.

30. Bassi J, Lau F (2013) Measuring value for money: a scoping review on economic evaluation of health information systems. J Am Med Inform Assoc 20: 792-801.

31. Buntin MB, Burke MF, Hoaglin MC, Blumenthal D (2011) The benefits of health information technology: a review of the recent literature shows predominantly positive results. Health Aff (Millwood). 30: 464-471.

32. Driessen J, Cioffi M, Alide N, Landis-Lewis Z, Gamadzi G, et al. (2013) Modeling return on investment for an electronic medical record system in Lilongwe, Malawi. J Am Med Inform Assoc 20: 743-748.

33. Gallego Al, Gagnon MP, Desmartis M (2010) Assessing the cost of electronic health records: a review of cost indicators. Telemed JE Health 16: 963-972.

34. Ventura ML, Battan AM, Zorloni C, Abbiati L, Colombo M, et al. (2011) The electronic medical record: pros and cons. J Matern Fetal Neonatal Med 24 Suppl 1: 163-166.

35. Robb D, Owens L (2013) Breaking free of copy/paste: OIG work plan cracks down on risky documentation habit. J AHIMA 84: 46-47. 